\title{
An alternative treatment for postcholecystectomy Mirizzi's syndrome: cystic duct balloon dilation
}
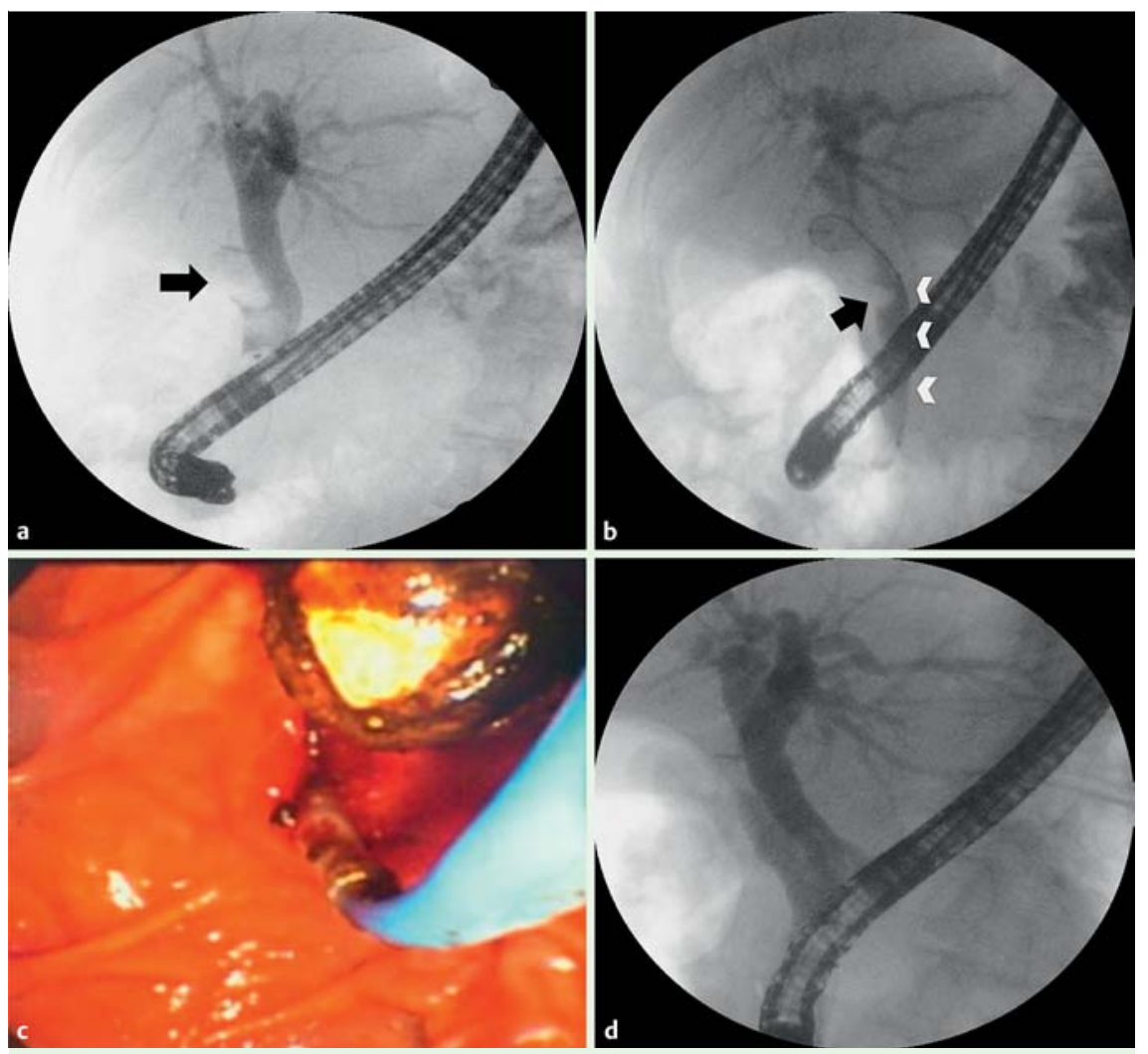

Fig. 1 Stone removal in postcholecystectomy Mirizzi's syndrome. a On balloon-occluded cholangiogram, a stone was observed in the cystic stump (black arrow). b The cystic duct was dilated using a large balloon (white arrows); the balloon's notch is seen at the level of the narrowed segment of the cystic duct (black arrow). c The stone was removed using an extraction balloon. $\mathbf{d}$ Stone removal was confirmed by cholangiography.

Postcholecystectomy Mirizzi's syndrome is an extremely rare condition that is caused by a stone in the cystic duct remnant. Remnant cystic duct calculus could be due to either a retained stone or recurrence of a stone [1]. A 68-year-old woman with jaundice, fever, and abdominal pain was admitted to our hospital. She had been diagnosed with type-1 Mirizzi's syndrome 8 months previously and had undergone laparoscopic cholecystectomy. Laboratory studies at our hospital revealed the following results: leukocyte count 27430 , alanine aminotransferase $88 \mathrm{U} / \mathrm{L}$, aspartate aminotransferase
$173 \mathrm{U} / \mathrm{L}$, gamma glutamyl transferase 484U/L, lactate dehydrogenase 624U/L, total serum bilirubin $7.36 \mathrm{mg} / \mathrm{dL}$, and direct serum bilirubin $5.67 \mathrm{mg} / \mathrm{dL}$.

She underwent endoscopic retrograde cholangiopancreatography (ERCP). During cholangiography, a stone measuring nearly $1 \mathrm{~cm}$ was observed at the junction of the common bile duct (CBD) and cystic duct stump, causing compression of the CBD ( $\bullet$ Fig. 1 a). The stone could not be extracted with a balloon or captured by a basket despite several attempts at retrieval. The junction of the CBD and cystic duct was therefore dilated using a 12-mm balloon
( $\bullet$ Fig. 1 b), and the stone was removed using an extraction balloon ( $\bullet$ Fig. 1 c). The removal of the stone was confirmed by cholangiography ( $\bullet$ Fig. $1 \mathrm{~d}$ ).

This is the first case in the literature describing balloon dilation at the junction of the CBD and cystic duct stump for the treatment of postcholecystectomy Mirizzi's syndrome. Although ERCP is traditionally used before surgery [2], we consider that this is an effective and safe alternative method for the treatment of postcholecystectomy Mirizzi's syndrome.

Endoscopy_UCTN_Code_TTT_1AR_2AH

Competing interests: None

Bülent Odemis, Erkin Oztaş, Muhammet Yener Akpınar, Serkan Torun, Ufuk Barıs Kuzu, Ertugrul Kayacetin

Gastroenterology Department, Türkiye Yüksek ihtisas Training and Research Hospital, Ankara, Turkey

\section{References}

1 Shaw C, O'Hanlon DM, Fenlon HM et al. Cystic duct remnant and 'postcholecystectomy syndrome'. Hepatogastroenterology 2004; 51: $31-38$

2 Zheng $M$, Cai W, Qin M. Combined laparoscopic and endoscopic treatment for Mirizzi syndrome. Hepatogastroenterology 2011; 58: 1099-1105

Bibliography

DOI http://dx.doi.org/

10.1055/s-0034-1392593

Endoscopy 2015; 47: E371

(c) Georg Thieme Verlag KG

Stuttgart · New York

ISSN 0013-726X

\section{Corresponding author}

Muhammet Yener Akpınar, MD

Gastroenterology Department

Türkiye Yüksek ihtisas Training and Research Hospital

Kizllay Street

06100 Sihhiye

Ankara

Turkey

Fax: $+90-312-4120$

muhammet.yener@gmail.com 